\title{
Correction to: Born to Enterprise? Entrepreneurial Intent Among Icelanders
}

\author{
Correction to: \\ Chapter 7 in: I. Minelgaite et al., Demystifying Leadership \\ in Iceland, Contributions to Management Science, \\ https://doi.org/10.1007/978-3-319-96044-9_7
}

The original version of Chapter 7 was inadvertently published without incorporating the author's proof corrections of removing the expanded "references citations" from the abstract so as to make it appear as below:

"In recent years, researchers and political figures have increasingly focused on entrepreneurship, emphasizing its role on economic and social growth and development, as well they have discussed how entrepreneurs can improve economies and people's lives by creating jobs, developing new solutions to problems, and creating technology that improves efficiency. In light of this discourse, this chapter covers the case of Iceland that is a matter of great relevance to the cultural characteristics as well as the economic turmoil that took place in the late 2008."

The chapter has now been corrected and approved by the author.

\footnotetext{
The updated online version of the chapter can be found at https://doi.org/10.1007/978-3-319-96044-9_7
} 